\title{
El principio de planeación como causal de nulidad absoluta de los contratos estatales: un análisis jurisprudencial desde el principio de taxatividad
}

\author{
The principle of planning as a cause of absolute nullity \\ of state contracts: a jurisprudential analysis from the \\ principle of taxation
}

\section{Mateo Zapata Granada}

\author{
Magíster en Derecho \\ Sección Tercera del Consejo de Estado - Colombia \\ mateo.zapata1@udea.edu.co
}

\begin{abstract}
Hugo Alberto López Duque (iD)
Especialista en Derecho Administrativo

Municipio de Caucasia - Colombia

hugoldabogado@hotmail.com
\end{abstract}

\footnotetext{
Cómo citar este artículo:

Zapata, M., y López, H. A. (2022). El principio de planeación como causal de nulidad absoluta de los contratos estatales: un análisis jurisprudencial desde el principio de taxatividad. Revista de la Facultad de Derecho y Ciencias Políticas, 52(136), pp. 124-154. doi: https://doi.org/10.18566/rfdcp. v52n136.a06
}

Recibido: 02 de noviembre de 2020

Aprobado: 31 de mayo de 2021 


\section{Resumen}

La contratación estatal, al igual que todas las actividades de la Administración Pública, es reglada, por lo que su funcionamiento debe someterse a lo establecido en el Estatuto General de Contratación. Entre las disposiciones que regulan la materia contractual, sobresale el principio de planeación, el cual busca que la contratación no sea el producto del azar o de la improvisación. La jurisprudencia, al desarrollar el alcance de este principio, ha determinado que es de obligatorio cumplimiento para todas las entidades públicas, y le ha definido diferentes consecuencias por su desconocimiento; entre ellas, la establecida en la Sentencia 27.315 del año 2013, según la cual el desconocimiento de la planeación deriva en la nulidad absoluta del contrato por objeto ilícito. Lo anterior, en oposición al principio de taxatividad, en virtud del cual las sanciones deben gozar de consagración positiva expresa. Por lo mismo, este trabajo, desde un enfoque metodológico positivista - analítico, desarrolla argumentos sólidos que defienden la tesis según la cual el desconocimiento de la planeación no puede conllevar a la nulidad del contrato, en tanto ello desdibuja el principio de taxatividad.

\section{Palabras clave}

Contratación estatal; nulidad absoluta de los contratos; objeto ilícito; principio de planeación; principio de taxatividad.

\section{Abstract}

State contracting, like all activities of the Public Administration, is regulated, therefore its operation must be subject to the provisions of the General Contracting Statute. The planning principle stands out among the provisions that regulate contractual matters, this one seeks for the contracting not to be a product of chance or improvisation.

When developing the scope of this principle, the jurisprudence has determined it as mandatory for all public entities and has defined different consequences due to is lack of awareness. Among them, the one established in Sentence 27.315 of 2013, according to which the planning unawareness results in the absolute nullity of the contract due to illicit object.

The foregoing, in opposition to the principle of taxation, by virtue of which the sanctions must enjoy expressly positive recognition.

For this reason, this work, from a positivist-analytical methodological approach, develops solid arguments that defend the thesis according to which planning unawareness cannot lead to the nullity of the contract, as this blurs the principle of taxation.

\section{Keywords}

State contracting; absolute nullity of the contracts; illegal object; principle of planning; principle of taxation. 


\section{Introducción}

Como lo ha definido la jurisprudencia de la Sección Tercera del Consejo de Estado, la contratación estatal es la herramienta o el instrumento por medio del cual se garantizan los fines del Estado, consagrados en el Artículo 2 de la Constitución Política. En palabras de la alta corporación, “[...] la causa del contrato estatal, esto es el motivo que da lugar a su celebración, es la satisfacción de las necesidades colectivas y de interés general a cuyo logro deben colaborar quienes contratan con la administración [...]” (Consejo de Estado, 2015, Sent. 24.636).

En la actualidad, la contratación pública en Colombia se encuentra regulada en el Estatuto General de Contratación de la Administración Pública, junto con sus modificaciones y sus reglamentaciones, esto es, la Ley 80 de 1993, la Ley 1150 de 2007, la Ley 1474 de 2011, el Decreto-Ley 019 de 2012, la Ley 1508 de 2012, la Ley 1882 de 2018, y el Decreto 1082 de 2015. Diferente a los estatutos contractuales anteriores (decretos-ley 150 de 1976 y 222 de 1983), que eran de un corte excesivamente reglamentario, la normativa actual es una ley de reglas, pero, especialmente, de principios, que define los lineamientos generales para el desarrollo de la compra pública en el país ${ }^{1}{ }^{2}$. De lo expuesto, se colige la importancia que adquirieron los principios en la contratación estatal, por cuanto delimitan el campo de acción de la Administración Pública.

Si bien el constituyente y el legislador tipificaron algunos principios, como los de la función administrativa (Artículo 209 de la Constitución), el de transparencia (Artículo 24 de la Ley 80 de 1993), y el de selección objetiva (Artículo 5 de la Ley 1150 de 2007), la jurisprudencia ha sido la encargada

1 En relación con esta afirmación, Dávila Vinueza (2003) explica que: "La Ley 80 de 1993 es una ley de principios, a diferencia del Decreto 222 de 1983, que era un cuerpo de reglas; en consecuencia, la lectura de ambos textos ha de hacerse de forma distinta, toda vez que en la teoría general del derecho la noción de principio es diferente de la de regla" (p. 20). En igual sentido, José Luis Benavides (2002) sostiene que: "La reglamentación excesiva de los contratos de la administración contenida en el antiguo estatuto, así como los imperativos económicos, orientaron al legislador hacia la simplificación de las reglas contractuales contenidas en un solo estatuto que, a diferencia del precedente, contendría solo grandes principios sobre la materia. Las entidades estatales podrían desarrollar su actividad contractual en un contexto de mayor libertad, para adaptarse mejor a las exigencias de eficacia de la administración [...]" (p. 66).

2 Aunque la doctrina mayoritaria considera que la Ley 80 de 1993 es una ley de principios, también es cierto que, como se indicó, en este cuerpo normativo se consagran reglas. No puede olvidarse que el Artículo 1 de la Ley 80, al definir su objeto, dispuso que "La presente ley tiene por objeto disponer las reglas y principios que rigen los contratos de las entidades estatales". Así, se reitera, si bien este nuevo estatuto consagra principalmente principios, también es una ley de reglas, así sea en menor medida que sus predecesores. 
de establecer el alcance de estas disposiciones. Incluso, ha creado principios nuevos, y les ha otorgado el carácter de verdaderas normas jurídicas. Sin duda, uno de los principios de creación jurisprudencial más importante es el de planeación, el cual tiene por finalidad que la contratación no sea el producto del azar o de la improvisación.

La observancia de este principio es indispensable para el desarrollo de la contratación pública, por cuanto facilita la materialización de los planes y de los proyectos diseñados por las diferentes entidades estatales. Su importancia radica, entre otras cuestiones, en que permite determinar la conveniencia o inconveniencia de adelantar un procedimiento de selección o de suscribir un negocio jurídico (Consejo de Estado, 2012, Sent. 21.489). Ciertamente, la planeación es uno de los mecanismos por medio de los cuales los demás principios de la contratación pueden hacerse efectivos, ya que, sin una debida planificación, no podrían alcanzarse los postulados de economía, de eficacia, de transparencia, de igualdad, de moralidad o de selección objetiva consagrados en las disposiciones vigentes.

Por mucho tiempo, la falta de planeación no derivó en consecuencias jurídicas para la existencia o para la validez del contrato estatal, por cuanto las consecuencias se limitaban a deficiencias en la etapa de ejecución o a responsabilidades fiscales, penales y disciplinarias para los servidores públicos que inobservaran este principio. No obstante, esto cambió en el año 2013, momento en el cual fueron proferidas las sentencias 27.315 del 24 de abril, 24.809 y 26.637 del 13 de junio, todas de la Subsección C de la Sección Tercera del Consejo de Estado, que diseñaron la tesis en virtud de la cual el desconocimiento de la planeación deriva en la nulidad absoluta del contrato por objeto ilícito.

Una teoría como la expuesta, entra en contradicción con el principio de legalidad de las sanciones, tipicidad o taxatividad, según el cual las sanciones, entre ellas las nulidades, deben ser de aplicación restrictiva, por lo que las interpretaciones extensivas o analógicas se encuentran proscritas. Bajo estos términos, la pregunta de investigación del presente escrito es la siguiente: ¿por qué el desconocimiento del principio de planeación no puede constituir una causal de nulidad absoluta de los contratos estatales, a partir del principio de taxatividad de las sanciones?

Esta investigación es de corte positivista - analítico, en tanto analizará la contradicción existente entre dos teorías del derecho: la que establece que la falta de planeación conlleva a la nulidad absoluta del contrato y la del principio 
de taxatividad de las sanciones. Sumado a ello, es una investigación cualitativa, dado que narrará las implicaciones del problema planteado a partir de datos documentales, especialmente, de la doctrina autorizada en la materia y de las sentencias proferidas por la Corte Constitucional y por el Consejo de Estado.

Teniendo en cuenta lo anterior, este trabajo abordará los siguientes cuatro tópicos: (i) la noción, el alcance y el fundamento del principio de planeación; (ii) la teoría desarrollada por la Subsección C de la Sección Tercera del Consejo de Estado, según la cual la falta de planeación vicia al contrato estatal de nulidad absoluta; (iii) el principio de taxatividad de las sanciones, y su relación con los principios de legalidad y debido proceso, y (iv) las variables teóricas y prácticas que se derivan de considerar que la inobservancia de la planeación constituye una causal de nulidad de los contratos estatales.

\section{La Noción, el alcance y el fundamento del principio de planeación en la contratación estatal}

Para entender el alcance o el sentido del principio de planeación, es necesario, en primer término, precisar la noción de principio. Los principios del derecho son una fuente por excelencia del sistema jurídico, que han sido abordados tanto por la doctrina, como por la jurisprudencia. Robert Alexy (2011), por ejemplo, al desarrollar su teoría de los derechos fundamentales, explica que los principios son mandatos de optimización, por lo que deben realizarse ““[...] en la mayor medida posible, de acuerdo a las posibilidades fácticas y jurídicas existentes"” (p. 12). La Corte Constitucional, por su parte, ha considerado que los principios guardan una triple finalidad: (i) configurar un ideal al que apunta el ordenamiento jurídico; (ii) ser un criterio de interpretación, y (iii) cumplir una función integradora (Corte Constitucional, Sent. C-284, 2015).

De esta forma, los principios, diferente a las reglas, le otorgan al operador jurídico un margen de maniobrabilidad más amplio, ya que permiten aplicaciones extensivas, que se adecuan a cada caso en concreto. En otros términos, representan esquemas normativos, que no contemplan la estructura tradicional de supuesto - consecuencia, sino que pueden resolver una gran variedad de problemas jurídicos, a partir de sus postulados, los cuales, por regla general, son de carácter abierto. Los principios del derecho son instituciones esenciales en el ordenamiento jurídico contemporáneo, pues permiten superar las lagunas y las antinomias que se generaban con la normativa basada en reglas. 
Ahora bien, para adentrarse en el principio de planeación, es pertinente señalar que este no goza de consagración positiva expresa, en tanto ha sido una creación de carácter jurisprudencial. Sobre este punto, la Sección Tercera explica que:

[...] si bien es cierto que el legislador no tipifica la planeación de manera directa en el texto de la Ley 80 de 1993, su presencia como uno de los principios rectores del contrato estatal es inevitable y se infiere: de los artículos 209, 339 y 341 constitucionales; de los numerales 6, 7 y 11 a 14 del artículo 25, del numeral 3 del artículo 26, de los numerales 1 y 2 del artículo 30, todos de la Ley 80 de 1993; y del artículo $2^{\circ}$ del Decreto 01 de 1984 [hoy, Ley 1437 de 2011]; según los cuales para el manejo de los asuntos públicos y el cumplimiento de los fines estatales, con el fin de hacer uso eficiente de los recursos y obtener un desempeño adecuado de las funciones, debe existir un estricto orden para la adopción de las decisiones que efectivamente deban materializarse a favor de los intereses comunales (Consejo de Estado, Sent. 55.855, 2017) ${ }^{3}$.

Como puede observarse, el principio de planeación se deriva de las disposiciones que regulan los planes de desarrollo; de la estructura de los procedimientos de selección, y de los demás principios de la contratación, como el de economía o el de selección objetiva ${ }^{4}$. En efecto, la obligación de escoger en debida forma al contratista, y de verificar los precios del mercado antes de iniciar con un procedimiento de selección, influyen en el deber de planeación, el cual recae en las autoridades y, como se explicará más adelante, en los contratistas. Bajo estos términos, el principio de planeación puede entenderse como:

3 Si bien la jurisprudencia citada explica el fundamento del principio de planeación en vigencia de la Ley 80 de 1993, lo cierto es que el Decreto 222 de 1983 también consagró un fundamento para el desarrollo previo de este principio. Así, el Artículo 84 de dicha normativa dispuso: "No podrá licitarse ni contratarse la ejecución de una obra sin que previamente se hayan elaborado los planos, proyectos y presupuesto respectivos y determinado las demás especificaciones necesarias para su identificación".

4 Frente a la relación existente entre el deber de planeación y los demás principios de la contratación, el Consejo de Estado ha indicado: "De otro lado, el cumplimiento del deber de planeación permite hacer efectivo el principio de economía, previsto en la Carta y en el artículo 25 de la Ley 80 de 1993, porque precisando la oportunidad y por ende teniendo la entidad estatal un conocimiento real de los precios de las cosas, obras o servicios que constituyen el objeto del contrato, podrá no solamente aprovechar eficientemente los recursos públicos sino que también podrá cumplir con otro deber imperativo como es el de la selección objetiva pues tiene la obligación de escoger la propuesta más favorable y la escogencia de esta también depende en últimas, como ya se vio, de la observancia del principio de planeación" (Consejo de Estado, Sent. 55.855, 2017). 
[...] el postulado de acuerdo con el cual la selección de contratistas, la celebración de los correspondientes contratos, así como la ejecución y posterior liquidación de los mismos, lejos de ser el resultado de la improvisación, deben constituir el fruto de una tarea programada y preconcebida, que permita incardinar la actividad contractual de las entidades públicas dentro de las estrategias y orientaciones generales de las políticas económicas, sociales, ambientales o de cualquier otro orden diseñadas por las instancias con funciones planificadoras en el Estado (Consejo de Estado, Sent. 8.031, 2008).

El contenido de este principio ha sido tan desarrollado por la jurisprudencia, que ha sido asociado con obligaciones concretas para la Administración Pública, entre ellas, las relacionadas con la correcta elaboración de los estudios y documentos previos. Ciertamente, toda entidad pública debe justificar la necesidad de adelantar el respectivo proceso de selección; debe explicar la modalidad que empleará para el efecto; debe elaborar las especificaciones técnicas, con sus correspondientes planos, diseños o análisis técnicos; debe calcular los costos de la eventual contratación, y debe contar con la disponibilidad presupuestal correspondiente (Consejo de Estado, Sent. $14.854,2007)^{5}$.

La Corte Constitucional, al estudiar el alcance de este principio, ha reproducido los planteamientos del Consejo de Estado, resaltando la importancia de realizar estudios previos adecuados, en tanto estos permiten

5 En un momento previo, el Consejo de Estado había expresado: "[...] las entidades oficiales están obligadas a respetar y a cumplir el principio de planeación en virtud del cual resulta indispensable la elaboración previa de estudios y análisis suficientemente serios y completos, antes de iniciar un procedimiento de selección, encaminados a determinar, entre muchos otros aspectos relevantes: (i) la verdadera necesidad de la celebración del respectivo contrato; (ii) las opciones o modalidades existentes para satisfacer esa necesidad y las razones que justifiquen la preferencia por la modalidad o tipo contractual que se escoja; (iii) las calidades, especificaciones, cantidades y demás características que puedan o deban reunir los bienes, las obras, los servicios, etc., cuya contratación, adquisición o disposición se haya determinado necesaria, lo cual, según el caso, deberá incluir también la elaboración de los diseños, planos, análisis técnicos, etc [sic]; (iv) los costos, valores y alternativas que, a precios de mercado reales, podría demandar la celebración y ejecución de esa clase de contrato, consultando las cantidades, especificaciones, cantidades de los bienes, obras, servicios, etc., que se pretende y requiere contratar, así como la modalidad u opciones escogidas o contempladas para el efecto; (v) la disponibilidad de recursos o la capacidad financiera de la entidad contratante, para asumir las obligaciones de pago que se deriven de la celebración de ese pretendido contrato; (vi) la existencia y disponibilidad, en el mercado nacional o internacional, de proveedores, constructores, profesionales, etc., en condiciones de atender los requerimientos y satisfacer las necesidades de la entidad contratante; (vii) los procedimientos, trámites y requisitos de que deban satisfacerse, reunirse u obtenerse para llevar a cabo la selección del respectivo contratista y la consiguiente celebración del contrato que se pretenda celebrar" (Consejo de Estado, Sent. 14.287, 2006). 
"[...] precisar el objeto del contrato, las obligaciones mutuas de las partes, la distribución de los riesgos y el precio, estructurar debidamente su financiación y permitir a los interesados diseñar sus ofertas y buscar diferentes fuentes de recursos" (Corte Constitucional, Sent. C-300, 2012).

Es de aclarar que, aunque el principio de planeación ha sido abordado por la jurisprudencia en mayor medida, la doctrina también ha precisado su alcance. Santofimio Gamboa (2009), por ejemplo, ha sostenido que, para asegurar el cumplimiento del principio de planeación, deben valorarse " $[\ldots]$ parámetros técnicos, presupuestales, de oportunidad, de mercado, jurídicos, de elaboración de pliegos y términos de referencia” (p. 43), en tanto así se garantizan la adecuada y continua prestación de los servicios públicos y la protección del patrimonio público.

Por otro lado, Rodrigo Escobar Gil (2003), al abordar la etapa de planificación, señala que:

[...] [l]a preparación del contrato estatal comienza con mucha antelación al momento que los entes públicos toman la decisión de celebrar un negocio jurídico en particular, puesto que esta etapa se encuentra estrechamente ligada con la elaboración de los planes y programas generales de gasto de inversión y con la formación del presupuesto. (p. 64).

Finalmente, Dávila Vinueza (2016) explica:

Como desarrollo de los principios de economía y de responsabilidad, el estatuto general de contratación confiere vital importancia a la fase previa 0 preparatoria de los procesos de selección. En particular los numerales 6,7 y 12 del artículo 25 y 3 del artículo 26 se refieren a esta fase que en definitiva integra el principio de planeación. La fase previa o preparatoria está dirigida a preparar todo lo necesario para el éxito de la licitación y del contrato. Se busca que las entidades realicen estudios de factibilidad, los diseños, los planos, obtengan las licencias, permisos y autorizaciones que el contrato requiera y elaboren pliegos de condiciones serios, objetivos y completos. De manera que una vez adjudicado y celebrado el contrato, se inicie su ejecución sin dilación alguna para que pueda ser cumplido dentro del plazo pactado. Atenta contra estos principios, las licitaciones con planos y diseños desactualizados, sin licencias y permisos o pliegos ambiguos, subjetivos e incompletos. Normalmente, cuando no dan al tratarse con la licitación, se erigen en los grandes perturbadores de la ejecución contractual (p. 781). 
Ahora bien, y teniendo en cuenta lo expuesto hasta el momento, resulta fundamental complementar las definiciones doctrinales y jurisprudenciales respondiendo los siguientes tres interrogantes: ¿el principio de planeación es una obligación que recae únicamente en la entidad pública?; cel deber de planeación opera de igual manera en todos los tipos contractuales?, y ila noción del principio de planeación guarda alguna conexión con las causales de nulidad absoluta de los contratos? Frente a la primera cuestión, tal y como se enunció en párrafos anteriores, y diferente a lo planteado por un sector de la doctrina, la planeación es un principio bifronte, es decir, que debe ser observado tanto por la entidad estatal como por el contratista. Ciertamente, el contratista, como colaborador de la Administración Pública, tiene el deber de contribuir para que el proceso contractual se desarrolle de la mejor manera posible. La desatención de esta obligación impide que, incluso, pueda invocarse posteriormente el desequilibrio económico del contrato, ya que no puede alegarse en la etapa contractual lo que no se observó en la etapa precontractual. Esta es la tesis de la Sección Tercera, que ha establecido lo siguiente:

Dentro del marco de la colaboración que compete al contratista, se encuentra igualmente sometido a respetar el principio de planeación, es decir, el contratista tiene la carga de analizar la suficiencia y consistencia de los estudios previos y de los precios presupuestados, en orden a definir su participación en la licitación y el contenido de su oferta; se entiende que es una carga, en el sentido de que el contratista no podrá desconocer los términos y condiciones que aceptó y mucho menos aquellos que negoció con la entidad pública (Consejo de Estado, Sent. 59.309, 2019) ${ }^{6}$.

Lo anterior, se explica de mejor manera con el siguiente caso hipotético: el municipio de Medellín pretende celebrar un contrato de obra con el fin de mejorar las instalaciones de algunas instituciones educativas. Sin embargo, las

6 En una providencia más reciente, el Consejo de Estado reprodujo estos planteamientos, así: "Es menester recordar que la responsabilidad de planeación se encuentra en cabeza de todos los actores que intervienen en la actividad contractual, es así que a la luz de lo establecido en el artículo 3 de la Ley 80 de 1993, la jurisprudencia del Consejo de Estado ha manifestado que los particulares que celebran y ejecutan contratos con las entidades estatales colaboran con ellas en el logro de sus fines y cumplen una función social que, como tal, implica obligaciones, y por consiguiente, de este precepto se desprende que el deber de planeación también abarca a estos colaboradores de la administración, puesto que no sólo tienen el deber de ponerle de presente a la entidad las deficiencias de planificación que adviertan para que sean subsanadas, sino que además deben abstenerse de participar en la celebración de contratos en los que desde entonces ya se evidencie que, por fallas en su planeación, el objeto contractual no podrá ejecutarse. Mucho menos podrán pretender los contratistas, en este último caso, el reconocimiento de derechos económicos puesto que esto sería tanto como aspirar al reconocimiento de una apropiación indebida de los recursos públicos" (Consejo de Estado, 2021, Sent. 42.135). 
especificaciones técnicas presentan varias deficiencias, que son evidentes para los posibles oferentes. Aunque suscribir el contrato en esos términos resulta imposible, ningún proveedor observa los pliegos de condiciones, comunicándole al municipio los errores cometidos en la ficha técnica. Al seguir el curso del proceso, el contrato es adjudicado al contratista X. Como era de esperarse, en la etapa de ejecución comienzan a presentarse dificultades, que se traducen en retrasos del cronograma y en una eventual suspensión del contrato.

El contratista pretende acudir al Artículo 27 de la Ley 80 de 1993, y solicita el restablecimiento de la ecuación contractual, invocando la ocurrencia de un hecho imprevisto, anormal y extraordinario ${ }^{7}$. En este caso, no sería procedente el restablecimiento del equilibrio económico, por varias razones: en primer lugar, porque, tal y como lo ha señalado la jurisprudencia de la Subsección A de la Sección Tercera, el desequilibrio ocurre al margen de que el contrato haya sido bien o mal planeado (Consejo de Estado, Sent. 59.309, 2019), lo cual significa que ambas instituciones son independientes; en segundo lugar, porque no le estaría dado al contratista invocar la ocurrencia de un hecho que era conocido al momento de presentar la propuesta, y que, es más, tuvo la posibilidad de observar o de cuestionar. Aceptar que los contratistas pueden ignorar su deber de planeación, implicaría un desconocimiento de los actos propios, y una violación del principio de buena fe, puesto que ellos consintieron ejecutar el contrato en unas condiciones, que, desde el punto de vista técnico y financiero, eran inviables.

Con relación a la segunda pregunta, esta también se responde en sentido negativo. Efectivamente, todos los contratos del Estado deben respetar los parámetros fijados por el principio de planeación, pero no en todos operan con la misma intensidad. De esta forma, no serán iguales las exigencias que deben cumplirse en un contrato de prestación de servicios, en uno de compraventa o en uno de suministro, que, por regla general, se limitan a una vigencia fiscal,

7 Como un ejercicio ilustrativo, resulta pertinente señalar que la teoría del equilibrio económico del contrato se presenta cuando acontecen hechos que, además de cumplir con los requisitos de anormalidad e imprevisión, hacen más gravosa la ejecución del contrato. Como lo expone la Sección Tercera: "[...] cualquiera que sea la causa que se invoque, se observa que el hecho mismo por sí solo no equivale a un rompimiento automático del equilibrio económico del contrato estatal, sino que deberá analizarse cada caso particular, para determinar la existencia de la afectación grave de las condiciones económicas del contrato". (Consejo de Estado, 2014, Sent. 24.809). Sumado a ello, para que opere el restablecimiento de la ecuación contractual, el hecho debe ser inimputable a la parte que lo invoca, lo cual significa que las causas del desequilibrio no pueden provenir de las actuaciones del contratista. Sobre este punto, Libardo Rodríguez (2011) afirma que "[...] para que una circunstancia que altera las condiciones contractuales genere la obligación de restablecimiento de la ecuación contractual, dicha circunstancia no puede ser imputable a la parte perjudicada" (p. 72). 
a las de un contrato de concesión, el cual, por naturaleza, se prolonga en el tiempo. Si bien la Corte Constitucional ha sostenido que en los contratos de concesión los estudios previos deben ser lo más precisos posibles, con el fin de asignar en debida forma los riesgos, y de definir un esquema financiero, también ha afirmado que este contrato es incompleto, lo cual impide prever todas las variables que pueden llegar a presentarse (Corte Constitucional, Sent. C-300, 2012).

Así, aunque las partes planifican algunos elementos de forma preliminar, es posible que, en el transcurso de la ejecución, se presenten situaciones que demanden adiciones o prórrogas, lo cual no puede traducirse en una falta de planeación. Justamente por esta situación, es que la planeación no se limita a la etapa precontractual, ya que en la etapa contractual e, incluso, en la de liquidación, pueden sobrevenir circunstancias que exigen la toma de decisiones que, en todo caso, no pueden ser improvisadas o mediocres, sino que deben obedecer a razonamientos serios y programados.

Finalmente, y frente al último interrogante, debe resaltarse que, de la doctrina y de la jurisprudencia analizada, no se desprende una relación entre el deber de planeación y las causales de nulidad absoluta de los contratos estatales, diferente a lo que ocurre entre dicho principio y las obligaciones de diseñar los estudios previos, de contar con las partidas o disponibilidades presupuestales correspondiente, de asignar correctamente los riesgos, y de hacer un análisis del mercado. Si bien este tema se abordará con mejor detalle en los títulos posteriores, desde ya debe advertirse que no existe, se reitera, ningún vínculo entre el mandato imperativo de planificar los contratos y el concepto de objeto ilícito.

Del estudio de la noción y del alcance del principio de planeación, puede colegirse la voluntad del constituyente, del legislador y de los jueces de imponerle a la Administración Pública, y a los particulares que colaboran con la misma, la obligación de racionalizar y organizar la actividad contractual, en tanto todo procedimiento de selección debe valorar aspectos técnicos, jurídicos, económicos y contables, que viabilicen el cumplimiento de los cometidos estatales. 


\section{Las consecuencias de inobservar el principio de planeación: una mirada a la tesis de la Subsección C de la Sección Tercera del Consejo de Estado".}

Como se indicó en la introducción de este texto, la inobservancia del principio de planeación, por regla general, no afectaba la validez del contrato estatal, por cuanto sus consecuencias se materializaban en deficiencias en la etapa de ejecución o en responsabilidades para quienes faltaran a dicho deber. De este modo, es común que los órganos de control fiscal o disciplinario sancionen a los empleados públicos que suscriben contratos sin la elaboración de los estudios previos, o con una deficiente asignación de los riesgos ${ }^{8}$. Un ejemplo de lo expuesto se identifica en la Sentencia del 25 de enero de 2018, en donde la Sección Segunda del Consejo de Estado aseveró:

La ausencia de estudios o la coexistencia de unos desactualizados o equivocados y la información errada en los sitos señalados de la obra, como sucedió en el caso bajo estudio, llevan a la pérdida de recursos, retrasos en la obra y mayores costos por los cuales debe responder la administración, lo que se traduce en un detrimento al erario. [...] Para la Sala, las actuaciones de la Procuraduría realizaron un recaudo probatorio que permitió individualizar los cargos formulados y motivar las decisiones en normas vigentes a los hechos, siendo no solo adecuadas y jurídicamente válidas, sino ejemplares por su calidad, su precisión y el cuidado sobresaliente con el cual dichos funcionarios acometieron esta investigación. [...] En suma los actos describen y puntualizan las circunstancias de modo, tiempo y lugar

8 Inclusive, la falta de planeación ha sido objeto de responsabilidad penal, en tanto el desconocimiento de este principio puede implicar la celebración de contratos sin el cumplimiento de los requisitos legales (artículo 410 del Código Penal). Por esta razón, la Corte Suprema de Justicia ha entendido que la planeación constituye un elemento esencial de los contratos. Al respecto, señaló: “El principio de planeación, ha dicho la Sala, resulta ser un requisito de la esencia de los contratos estatales, según dimana del artículo 25, numeral 12 de la Ley 80 de 1993, conforme al cual la administración está obligada a realizar los estudios, diseños y proyectos requeridos y elaborar los pliegos de condiciones o términos de referencia con antelación al procedimiento de selección del contratista o a la firma del contrato, exigencia que se explica en la medida que 'la contratación administrativa no es, ni puede ser, una aventura, ni un procedimiento emanado de un poder discrecional, sino, por el contrario, es un procedimiento reglado en cuanto a su planeación, proyección, ejecución e interventoría, orientado a impedir el despilfarro de los dineros públicos'" (Corte Suprema de Justicia, 2013, Sent. 41.665). Asimismo, la alta corporación ha explicado que: "De suerte que si un contrato estatal, incluido el de prestación de servicios por vía directa, se celebra sin estar precedido del respectivo análisis o estudio de conveniencia y oportunidad, se incumple un requisito esencial a su tramitación. Y esto realiza objetivamente el tipo penal previsto en el art. 410 del CP" (Corte Suprema de Justicia, 2016, Sent. 46.037). 
en que sucedió la conducta atribuida, señalan las normas constitucionales y legales vulneras [sicl en cada caso en particular, analizan el deber funcional de la encartada y sus respectivos resultados, que con llevaron [sic] a la vulneración de los principios contractual consagrados en los artículo [sic] 24, 25 y 26 de la Ley 80 de 1993 (Consejo de Estado, 2018, Sent. 1501-12).

Sin embargo, esta situación varió en el año 2013, cuando la Subsección C de la Sección Tercera del Consejo de Estado diseñó una tesis, según la cual el desconocimiento del deber de planeación vicia el contrato estatal de nulidad absoluta. Si bien en oportunidades anteriores el Consejo de Estado ya había declarado la nulidad por la inobservancia de algún principio, esto solo ocurría frente aquellos consagrados de manera expresa en la Constitución o en la ley. Así, la alta corporación consideraba que suscribir un contrato sin el cumplimiento del principio de transparencia, constituía un objeto ilícito, en tanto se transgredía el derecho público de la nación; por su parte, inobservar el principio de selección objetiva, viciaba el contrato por desviación de poder (Consejo de Estado, 2012, Sent. 22.471) ${ }^{9}$.

Precisado lo anterior, resulta necesario estudiar las sentencias 27.315, 24.809 y 26.637, con el fin de identificar los principales argumentos que sustentan la ya mencionada teoría. Por la similitud fáctica y jurídica que guardan estas providencias, serán explicadas de manera conjunta. En general, los tres fallos abordan el mismo supuesto: contratos de obra que no pudieron ejecutarse, o que se ejecutaron de manera tardía, debido a que la entidad no adquirió previamente los predios en donde estas serían construidas. Para la Subsección C, en estos casos, los contratos se encontraban viciados de nulidad absoluta, debido a que fueron mal planificados, lo cual constituye una transgresión del orden jurídico, que configura el objeto ilícito. En los tres pronunciamientos, luego de analizar el alcance del principio de planeación, el alto tribunal coligió que:

En consecuencia, cuando la ley de contratación estatal dispone que debe observarse el principio de planeación, la elusión de este mandato comporta

9 En relación con esta afirmación, debe hacerse la siguiente claridad: no en todo caso que se desconozca el deber de selección objetiva, el contrato se viciará de nulidad por desviación de poder (numeral 3 del Artículo 44 de la Ley 80), por cuanto es posible que se configuren otras causales, como la de celebrar el contrato en contra de expresa prohibición constitucional o legal (numeral 2 del Artículo 44). De este modo, en cada caso deberá determinarse si en el contrato se eludieron los procedimientos de selección, caso en el cual se configuraría la causal del numeral 2 del Artículo 44, o si el comportamiento de los funcionarios desconoce un mandato imperativo, momento en el cual se configura la causal del numeral 3 (Consejo de Estado, 2017, Sent. 50.045). 
una transgresión al orden legal que conduce a la nulidad absoluta del contrato por ilicitud del objeto porque de acuerdo con el derecho común esto es lo que se configura en todo acto que contraviene al derecho público (Consejo de Estado, 2013, Sents. 27.315, 24.809 y 26.637).

Por supuesto, no toda falta a la planeación vicia el contrato de nulidad absoluta, por cuanto solo aquellas falencias que impidan la ejecución del contrato; que condicionen su ejecución a situaciones inciertas o imprevistas, o que representen mayores gastos para la entidad, tendrán la virtualidad de configurar un objeto ilícito.

En estas providencias, el Consejo de Estado analizó, además, el principio de la no reformatio in pejus, y la posibilidad de que el juez declare la nulidad de manera oficiosa. En relación con este tema, la sala consideró que la declaratoria de nulidad, al propender por la conservación del orden jurídico, debe prevalecer ante los intereses subjetivos que se protegen con aquel principio del derecho procesal:

[...] si en el trámite de la segunda instancia, que se surte en virtud del recurso de un apelante único, se advierte una causal de nulidad absoluta, es poder-deber del juez el decreto oficioso de ella porque se lo impone el control de legalidad que el ordenamiento le manda en aras de la protección del interés general que envuelve la defensa del orden público y las normas imperativas. Por lo tanto, jamás podrá decirse que, en un caso como el que se acaba de mencionar, el decreto oficioso de la nulidad absoluta lleve consigo la violación del principio de la reformatio in pejus porque la protección del orden jurídico es un interés general que debe prevalecer sobre el interés particular que contiene el principio de no reformar la sentencia en perjuicio del apelante único (Consejo de Estado, 2013, Sents. 27.315, 24.809 y 26.637).

Como era de esperarse, esta tesis no fue pacífica al interior de la Subsección C de la Sección Tercera, en tanto contó con el salvamento de voto del consejero Enrique Gil Botero, quien expuso dos razones para apartarse de la decisión mayoritaria: en primer término, para el consejero disidente, la declaratoria de nulidad del contrato transgrede el antes mencionado principio de la no reformatio in pejus, en tanto el juez de segunda instancia solo tiene competencia para pronunciarse frente a aquellos asuntos que fueron objeto del recurso de apelación, lo cual le impide decretar situaciones más gravosas para el apelante único, como lo es la nulidad. Si bien la nulidad absoluta se 
contempla como una institución enmarcada en la protección del orden legal, este no puede prevalecer sobre las garantías constitucionales, entre ellas, las que componen el debido proceso ${ }^{10}$.

En segundo lugar, el consejero aseguró que el precedente establecido por la Subsección C era peligroso, por cuanto creaba el imaginario de que la obtención de los predios o de los terrenos debía ser un requisito previo a la celebración del contrato, lo cual enrigidecía la práctica contractual, especialmente, en los contratos más complejos, como los de concesión. En todo caso, indicó que los asuntos relacionados con la no adquisición de los predios debían discutirse en el plano del incumplimiento, mas no en el de la nulidad.

Ahora bien, en contra de la Sentencia 24.809 del 13 de junio de 2013, el demandante (CONCONCRETO S.A.) interpuso una acción de tutela, la cual fue conocida, en primera instancia, por la Sección Cuarta, y, en segunda instancia, por la Sección Quinta. El juez de primera instancia, luego de analizar los requisitos generales y específicos de la tutela en contra de providencias judiciales, determinó que la Subsección C incurrió en un yerro (defecto sustantivo, por interpretación errónea), en tanto le dio un entendimiento equivocado a la noción de objeto ilícito.

Si bien este es un concepto jurídico indeterminado, su alcance no puede ser fijado por el juez de manera discrecional o arbitraria. Ciertamente, esta causal de nulidad solo opera cuando "[...] las prestaciones pactadas en el contrato, esto es, el objeto del contrato, atentan contra el ordenamiento jurídico o las buenas costumbres" (Consejo de Estado, 2014, Sent. del 21 de agosto). De esta forma, la ilicitud solamente se predica de las prestaciones del negocio jurídico, sin que este análisis pueda extenderse a las situaciones ocurridas en la etapa precontractual. En palabras de la alta corporación:

A juicio de esta Sala, la violación del principio de planeación, por una parte, no es una causal autónoma o directa de nulidad del contrato y, por otra, no encaja en la configuración de un verdadero caso de objeto ilícito. En efecto, la ilicitud que la sentencia encontró probada se trasladó del objeto del contrato propiamente dicho a la etapa previa a la celebración, en cuanto exigió que,

10 El tenor literal de lo expuesto es el siguiente: "En ese orden de ideas, la defensa acérrima del principio de legalidad tiene que ceder ante las garantías constitucionales modernas, de manera concreta, frente a aquellas que se relacionan con derechos fundamentales, dentro de las cuales se encuentra el principio de la no reforma en peor" (Consejo de Estado, 2013, Salvamento de voto de la Sent. 24.809). 
en últimas, ambas partes debían tener certeza de la disponibilidad de los predios, antes de celebrar el contrato de obra. Es decir, que halló probada una supuesta ilicitud en la fase previa a la celebración del contrato y no propiamente en las cláusulas de lo que sería el contrato (Consejo de Estado, 2014, Sent. del 21 de agosto).

La Sección Cuarta, al igual que el consejero Gil Botero, consideró que la ausencia de planeación debe discutirse en el plano del incumplimiento, pues aquella "[...] puede generar responsabilidad por incumplimiento, si esa falta de planeamiento malogra la cumplida ejecución del contrato. Y esa responsabilidad le puede caber tanto al contratante como al contratista, según la posición jurídica en que se encuentren frente a cada obligación” (Consejo de Estado, 2014, Sent. del 21 de agosto). Bajo estos términos, el juez de tutela dejó sin efectos el fallo de la Subsección C, y le ordenó expedir una nueva providencia.

Dicha decisión fue impugnada y conocida en segunda instancia por la Sección Quinta del Consejo de Estado, quien confirmó el fallo, reproduciendo los argumentos de la Sección Cuarta. En particular, señaló que:

[...] la declaratoria de nulidad que del contrato objeto de estudio realizó la Sección Tercera, se fundó en un razonamiento sobre el objeto ilícito contractual sin que los supuestos sobre los que lo halló configurado se acomodaran en realidad a dicha figura. En efecto, lo pactado en el caso concreto, de entrada, no evidenciaba un contenido ilícito prestacional, más bien determinaba el marco general que debió interesar a la autoridad judicial accionada en aras de establecer si no existió [sic] o no el presunto incumplimiento contractual (Consejo de Estado, 2014, Sent. del 27 de noviembre).

Como consecuencia del fallo de tutela, la Subsección C de la Sección Tercera del Consejo de Estado profirió la Sentencia del 20 de octubre de 2014, en donde destinó algunos apartes para refutar las consideraciones de la Sección Cuarta. En efecto, la sala inició recordando que “[...] toda violación a un mandato imperativo o a una prohibición de la ley, comporta un vicio que genera [la] nulidad absoluta [...]", por lo que "[...] no es cierto que para que un acto o contrato sea absolutamente nulo por objeto ilícito es indispensable la existencia de una norma que diga, expresa y sacramentalmente, que 'es nulo' [...]" (Consejo de Estado, 2014, Sent. 24.809).

En igual sentido, aseguró que el juez de tutela se equivocó al confundir el objeto del contrato con el objeto de la obligación, puesto que, mientras 
el primero es el derecho materia de regulación, el segundo es la conducta comisiva u omisiva a cargo del deudor. Para la Subsección C, la confusión del juez de tutela conlleva a una falencia, consistente en "[...] creer que los contratos sólo producen obligaciones cuando es elementalmente sabido que ellos también pueden regularlas o extinguirlas como de manera paladina lo dice el artículo 864 del Código de Comercio” (Consejo de Estado, 2014, Sent. 24.809). De este modo:

Incurrir en semejantes confusiones conceptuales puede conducir, como en efecto ocurre y ha ocurrido en este caso, a negar la existencia de un objeto ilícito cuando un contrato se celebra en circunstancias contrarias a las ordenadas imperativamente por la ley, tal como sería el caso de no observar el principio de planeación en la celebración de los contratos estatales (Consejo de Estado, 2014, Sent. 24.809).

A pesar de los esfuerzos del consejero ponente, la tesis de la Subsección C fue derrotada, por lo que, en principio, esta no podría reproducirse en pronunciamientos posteriores. Empero, existen providencias en donde la misma subsección ha reiterado lo planteado en los fallos del año 2013. Así, por ejemplo, en la Sentencia del 10 de diciembre del año 2015, se señaló que:

Entonces, el desconocimiento del principio de planeación podría llevar al contrato a incurrir en una violación a la normatividad que la impone, incluso, a encajarse en un evento de objeto ilícito, cuando se estén contraviniendo las normas imperativas que ordenan que los contratos estatales deben estar debidamente planeados para que el objeto contractual se pueda realizar y finalmente se pueda satisfacer el interés público que envuelve la prestación de los servicios públicos (Consejo de Estado, Sent. 51.489, 2015).

Si bien el fallo de tutela de la Sección Cuarta tenía efectos inter partes, se considera importante que la Sección Tercera, especialmente, la Subsección C, abandone aquellas tesis que, a la luz del juez constitucional, son contrarias a los derechos de acceso a la administración de justicia y debido proceso. Aunque en este caso, paradójicamente, el juez revocó la declaratoria de nulidad proferida por el a quo (por considerar que la falta de planeación del contrato estudiado no era de tal magnitud que viciara el objeto), es peligroso que en el ordenamiento jurídico persistan teorías tan dañinas para el funcionamiento ágil de la Administración. Es de resaltar que las demás subsecciones de la Sección Tercera, e incluso la misma Subsección C luego de la salida del consejero Santofimio Gamboa, le han dado una lectura diferente al principio de 
planeación, abordando su relación con el incumplimiento del contrato. De esta temática se hablará en el título cuarto de este escrito.

Planteadas todas estas cuestiones, se procederá a estudiar el concepto de nulidad absoluta, y su relación con el principio de taxatividad. Lo anterior, con el fin de determinar si la declaratoria de nulidad por transgresión del principio de planeación, implica un desconocimiento del carácter taxativo de las sanciones.

\section{El principio de taxatividad de las sanciones y su relación con el principio de legalidad y con el derecho al debido proceso}

Como se expuso en el título anterior, el Consejo de Estado le otorgó al principio de planeación la virtualidad de viciar los contratos estatales de nulidad absoluta. Ello, por supuesto, demanda la necesidad de precisar las nociones de nulidad absoluta y de objeto ilícito, con el fin de determinar si, efectivamente, una interpretación planteada en los términos de la Subsección C transgrede el principio de taxatividad, el cual es una expresión del principio de legalidad y del derecho al debido proceso.

La nulidad, como lo explica Matallana Camacho (2013), es una figura sancionatoria propia del derecho civil, que fue incluida en la contratación estatal, por cuanto no era justificable crear un régimen de nulidades diferente al del derecho común. Lo que hace el Artículo 44 de la Ley 80 de 1993, además de remitir a las causales de nulidad del derecho privado, es crear algunas causales adicionales, que obedecen a las lógicas propias del derecho administrativo. Entre ellas, se encuentran la de celebrar el contrato con personas incursas en causales de inhabilidad o de incompatibilidad, o la de celebrar el contrato con desviación de poder.

De este modo, para aplicar el régimen de las nulidades, especialmente, el de la nulidad absoluta, debe tenerse presente el Artículo 1741 del Código Civil, el cual dispone:

La nulidad producida por un objeto o causa ilícita, y la nulidad producida por la omisión de algún requisito o formalidad que las leyes prescriben para el valor de ciertos actos o contratos en consideración a la naturaleza de ellos, 
y no a la calidad 0 estado de las personas que los ejecutan o acuerdan, son nulidades absolutas. Hay, así mismo, nulidad absoluta en los actos y contratos de personas absolutamente incapaces. Cualquiera otra especie de vicio produce nulidad relativa, y da derecho a la rescisión del acto o [del] contrato.

Es de aclarar que la nulidad absoluta, diferente a la nulidad relativa, busca proteger el interés general y el orden jurídico, por lo que solo opera frente a aquellos vicios que son insanables. En los términos de Dávila Vinueza (2016), quien cita a la doctrina civilista, "[...] la nulidad absoluta se enderezaría a proteger el interés general de la sociedad” (p. 745). Yong (2013), por su parte, asevera que la nulidad absoluta se presenta cuando el contrato "[...] carece de valor por haberse celebrado con vicios tan graves, que la ley no permite sanearlo por razones de protección de interés general” (p. 239). Finalmente, la Sección Tercera del Consejo de Estado plantea que:

La nulidad absoluta de los contratos se refiere, entonces, a su pérdida de validez con ocasión de vicios imposibles de sanear, y se constituye en la más grave sanción que se pueda imponer a los negocios jurídicos por cuanto hace desaparecer sus efectos al buscar devolver las cosas al estado en el que se encontraban con anterioridad a la suscripción del contrato (Consejo de Estado, 2011, Sent. 17.767).

Ahora bien, el objeto ilícito es una de las causales de nulidad absoluta de los contratos, el cual se encuentra regulado en el Artículo 1519 del Código Civil, que prescribe: "Hay un objeto ilícito en todo lo que contraviene al derecho público de la nación [...]”. En relación con esta institución, Ospina Fernández y Ospina Acosta (2014) han señalado lo siguiente:

Entre las condiciones que debe reunir el objeto de todo acto jurídico, además de su posibilidad y determinación, está la de ser lícito, esto es, conforme a la ley, al orden público y a las buenas costumbres. Por consiguiente, el objeto ilícito, sancionado con nulidad absoluta, se configura cuando el acto, en sus prestaciones aisladamente consideradas o en su conjunto, contraría cualquiera de los extremos mencionados: la ley, el orden público, o las buenas costumbres (p. 439).

Tal vez una de las características más importantes del objeto ilícito, al igual que del resto de las causales de nulidad, radica en que el legislador es el único competente para definir su alcance. En efecto, la cláusula general de competencia en materia legislativa, consagrada en el Artículo 150 de la 
Constitución, le permite al Congreso de la República determinar las causales, los efectos, y las demás condiciones de las nulidades. Como lo indica la jurisprudencia constitucional:

En ese orden de ideas, esta Corporación en reiterada jurisprudencia ha señalado en relación con la institución de las nulidades, que corresponde al órgano legislativo fijar las causales, la legitimidad para alegarlas, oportunidad de hacerlo [sic] forma de probarlas, el alcance de las mismas, y en general las reglas aplicables a las circunstancias en que surgen, así como lo que atañe a sus efectos (Corte Constitucional, 2001, Sent. C-709).

Esta característica de la institución de las nulidades demanda un importante cuestionamiento en relación con la tesis de la Subsección C, ya que el juez fue quien concluyó, a partir de una interpretación ampliada del Artículo 1519 del Código Civil, que desconocer el mandato imperativo de planificar los contratos, implicaba una violación del derecho público, lo cual era castigable con la nulidad absoluta.

Aunque el juez de lo contencioso administrativo es competente para interpretar las diferentes disposiciones del ordenamiento jurídico, determinar el sentido de las nulidades escapa de sus atribuciones, lo cual, se reitera, es competencia exclusiva del legislativo. Pretender lo contrario, desgarraría las fibras del Estado Social y Democrático de Derecho, por cuanto el juez, bajo la excusa de aplicar la ley, crearía sanciones no contempladas de manera previa y expresa en el ordenamiento jurídico.

Lo expuesto hasta este punto, representa una transgresión del principio de taxatividad, en virtud del cual las sanciones son de aplicación restrictiva, lo cual prohíbe las interpretaciones extensivas o analógicas. La Corte Constitucional, al abordar el contenido general de este principio, ha precisado:

El principio de legalidad de las sanciones exige que estas estén determinadas en el momento de cometer la infracción. Quien lleva a cabo una conducta legalmente prohibida bajo apremio de sanción penal 0 administrativa debe conocer previamente cuál es el castigo que acarrea su comportamiento. Este castigo no puede quedar a la definición ulterior de quien lo impone, pues tal posibilidad desconoce la garantía en contra de la arbitrariedad (Corte Constitucional, Sent. C-475, 2004). 
En igual sentido, la Sección Tercera del Consejo de Estado, al estudiar el tema específico de las nulidades, ha señalado que:

[...] las normas que imponen sanciones o establecen prohibiciones, al igual que ocurre con las que consagran nulidades, son de carácter taxativo y de interpretación restrictiva, por consiguiente, en relación con ellas no cabe su interpretación extensiva o su aplicación por vía de analogía (Consejo de Estado, Sent. 15.324, 2007).

Cabe mencionar que este alcance del principio de taxatividad, se reitera, guarda una relación estrecha con el principio de legalidad y con el derecho al debido proceso, en tanto es imperativo de los procedimientos judiciales respetar las garantías procesales, y actuar conforme al derecho vigente. Si bien es cierto que el Estado puede ejercer una potestad sancionatoria, esta no es absoluta, ya que los postulados en contra de la arbitrariedad demandan el respeto de los preceptos constitucionales.

De esta forma, el Consejo de Estado erró al declarar la nulidad absoluta de los contratos analizados en las sentencias 27.315, 24.809 y 26.637, en tanto desconoció el hecho innegable de que el legislador, al regular las causales de nulidad absoluta de los contratos estatales, no valoró el desconocimiento del principio de planeación. Como este principio no goza de consagración positiva expresa, su conceptualización obedece a las interpretaciones de los jueces. Por lo mismo, otorgarle la posibilidad de viciar los contratos, desconoce la prohibición de aplicar sanciones por intermedio de interpretaciones ampliadas.

Si bien es cierto que el Artículo 1519 del Código Civil prescribe que: es objeto ilícito todo lo que contravenga el derecho público de la nación, esta definición posterior de qué se entiende por derecho público, está en manos del legislador, siendo imposible que el juez enmarque cualquier desatención de un precepto normativo en dicha causal de nulidad.

Aunque la Subsección C, al defender su tesis, planteó que no es necesario que una disposición consagre -de manera expresa- cuáles conductas derivan en la nulidad del contrato, esto no es de recibo, puesto que atenta contra el ya mencionado principio de taxatividad que las personas no tengan claridad frente a las circunstancias que podrían generarles una sanción. No puede olvidarse que la nulidad absoluta es la sanción más rigurosa para un contrato, lo cual impide que su configuración obedezca a los caprichos del juez, aun cuando este sea el supremo tribunal de la jurisdicción de lo contencioso administrativo. 
Planteado el alcance del principio de taxatividad de las sanciones, al igual que las razones por la cuales la tesis de la Subsección C de la Sección Tercera lo desconoce, es necesario identificar las variables teóricas y prácticas que se desprenden de considerar que la falta de planeación vicia el contrato estatal de nulidad absoluta.

\section{Variables teóricas y prácticas que se derivan de considerar que la falta de planeación vicia el contrato estatal de nulidad absoluta}

En este último título se identificarán las particularidades teóricas y prácticas relacionadas con la tesis de la Subsección C de la Sección Tercera del Consejo de Estado. En primer término, y como ya se explicó, es claro que considerar que la falta de planeación constituye una causal de nulidad absoluta de los contratos, desconoce el carácter taxativo de las sanciones, lo cual implica un desconocimiento del derecho al debido proceso. Esta es, sin duda, la deficiencia conceptual más importante de esta teoría, por cuanto fundamenta una sanción a partir de interpretaciones jurisprudenciales, sin contar con el respaldo de una disposición positiva.

No obstante, esta tesis encuentra otras variables teóricas, que vale la pena resaltar. En el título segundo se enunció que, desde la salida del consejero Santofimio Gamboa, el Consejo de Estado ha replanteado el alcance del desconocimiento del principio de planeación, relacionándolo con la institución del incumplimiento. En efecto, para un sector de la jurisprudencia actual, y tal como lo había planteado el salvamento de voto del consejero Gil Botero, las controversias relacionadas con la planeación deben ventilarse en el escenario del incumplimiento, mas no en el de las nulidades.

Lo anterior, representa un nuevo marco conceptual, y plantea las verdaderas consecuencias que se derivarían de desconocer el mandato imperativo de planificar los contratos. Como las deficiencias en la planeación se reflejan en la etapa de ejecución, todos los retrasos o sobrecostos que se presenten en un contrato, y que se deriven de aquella falta, se considerarán incumplimientos. La cuestión radicará en determinar quién debe asumir dicho incumplimiento, valorando el carácter bifronte del principio de planeación. 
El Consejo de Estado ha aseverado que el incumplimiento emana del desconocimiento de las cláusulas contractuales, de la desatención de los estudios y documentos previos, y de la transgresión de los principios de la contratación (Consejo de Estado, 2020, Sent. 44.420). Por lo mismo, si la entidad estatal, pese a la juiciosa participación del contratista, incurre en una mala planeación, que conlleva a un incumplimiento de las obligaciones, deberá indemnizar los daños causados al contratista. Por supuesto, no cualquier falencia en la planeación dará lugar a un incumplimiento, sino que deberá establecerse la relación directa entre dicha falta, las obligaciones incumplidas, y los daños generados al contratista (Consejo de Estado, 2020, Sent. 45.816).

Este asunto podría entenderse de mejor manera con el siguiente ejemplo: el municipio de Bello pretende celebrar un contrato de obra, con el fin de construir el intercambio vial "La Madera". Para ello, establece -en el pliego de condiciones- que los diseños de la obra estarán a cargo del ente territorial; asimismo, en la audiencia de asignación de riesgos, de que trata el Artículo 4 de la Ley 1150 de 2007, determina que asumirá los riesgos derivados del retraso en la entrega de los diseños.

Una vez iniciada la ejecución del contrato, el municipio incumplió con la precitada obligación, generando demoras en la construcción de la obra. En este caso, la entidad incurrió en un yerro al momento de estructurar los documentos previos, por cuanto le dio apertura al proceso de selección sin calcular adecuadamente los tiempos requeridos para la elaboración de los diseños. Frente a este panorama, es pertinente preguntar iquién debería asumir los costos generados por los atrasos en la obra? En relación con este interrogante, existen dos posibles respuestas. La primera, en virtud de la cual la entidad estatal debe responsabilizarse de los retardos del contrato, y debe indemnizar al contratista, por cuanto dichos retrasos se debieron a una conducta que era de su responsabilidad exclusiva. Sobre este tema, el Consejo de Estado ha expresado:

[...] resultaría contrario a derecho asignar al contratista aquellos riesgos cuya concreción se derivara [sic] directamente de la voluntad exclusiva de la entidad contratante y que tuvieran la virtualidad de afectar la normal ejecución del contrato. Tal sería el caso de los supuestos de incumplimiento contractual que bien podría encuadrarse cuando esta se aparta de su obligación de planeación. Sentado lo expuesto, cabe precisar que, aun cuando la planeación que se debe observar en la etapa previa a la celebración del contrato se demanda respecto de ambos extremos precontratantes, lo cierto 
es que ello es así en función de las cargas y responsabilidades que cada uno asuma en relación con la naturaleza y el contenido de las obligaciones que se contraen con ocasión de la celebración del acuerdo (Consejo de Estado, 2020, Sent. 61.500).

La segunda, por su parte, plantea que el contratista no tiene derecho a la indemnización de perjuicios, ya que tenía la obligación de advertir los errores cometidos por la entidad en la etapa precontractual. Bajo estos términos, el contratista debió prever que los diseños no estarían listos para el inicio del contrato, por lo que, como experto en la materia, debía abstenerse de participar en el proceso de selección. Como lo explica la Subsección B:

Si el contratista tenía algún tipo de prevención sobre el alcance de la obligaciones contractuales, y sobre la verdadera posibilidad de cumplir el objeto contractual, dada la información y los estudios que había adelantado previamente la entidad [...], debió manifestarlo desde la etapa precontractual, habida cuenta de que, tal y como lo ha señalado el Consejo de Estado en diversas oportunidades, el contratista tiene el deber de colaborar con la administración, en observancia del principio de planeación, de manera que, entre otros, les corresponde ponerle de presente a la entidad las deficiencias de planificación que adviertan para que sean subsanadas, además deben abstenerse de participar en la celebración de un contrato en el que evidencien que, por fallas en su planeación, el objeto contractual no podrá ejecutarse. De manera entonces que no se observa ninguna obligación contractual que haya sido incumplida por la entidad contratante, lo que llevará a la Sala a denegar, de igual manera, esta segunda pretensión (Consejo de Estado, 2020, Sent. 48.676).

En este último fallo, el Consejo de Estado afirmó, incluso, que no puede hablarse de incumplimiento cuando los problemas de ejecución son generados por situaciones ocurridas en la etapa de planificación. Este texto no comparte este último planteamiento, porque, si bien en la etapa preparatoria del contrato no se está en presencia de estipulaciones contractuales, no puede olvidarse que lo plasmado en los documentos previos, y los aciertos o errores que ellos contengan, son trasladados posteriormente al clausulado que regula la relación negocial. Por lo mismo, situaciones originadas en el desconocimiento del deber de planeación, tendrían la virtualidad de ser discutidas en sede de incumplimiento.

Analizadas las dos posturas, se considera más acertada la primera, pues es razonable que la entidad asuma los perjuicios derivados de su propia 
negligencia. Si bien es cierto que los contratistas deben avizorar los errores cometidos por el Estado, esta obligación no puede servir de argumento para trasladarle a la parte más débil del vínculo contractual todas las consecuencias negativas que se desprenden de un contrato mal planeado. El contratista solo debe afrontar las cargas que, valorando la naturaleza de las prestaciones, está en condiciones de asumir.

Ahora bien, es pertinente retomar, además, la relación existente entre la falta de planeación y el rompimiento del equilibrio económico del contrato. Ya en el título primero se señaló, de manera tangencial, que, en virtud de la jurisprudencia vigente, ambas instituciones son independientes, y ello se debe al esfuerzo que ha realizado la Sección Tercera por distinguir los efectos del incumplimiento de los de la teoría del equilibrio económico.

Si bien el Artículo 5 la Ley 80 de 1993 considera que el incumplimiento es una causa del desequilibrio económico, la jurisprudencia del Consejo de Estado ha sostenido que ello constituye un error del legislador, pues el incumplimiento obedece a otras causas y genera otro tipo de consecuencias. Ciertamente, el desequilibrio se fundamenta en actuaciones lícitas, esto es, el uso de las prerrogativas de la Administración o la ocurrencia de situaciones ajenas a las partes. Por el contrario, el incumplimiento de las obligaciones transgrede el ordenamiento jurídico, por lo que no puede habilitar el restablecimiento del sinalagma contractual. Sumado a ello, los efectos de ambas figuras son diferentes, puesto que, mientras en el desequilibrio se busca recuperar la conmutatividad del contrato, en el incumplimiento se pretende la ejecución de las obligaciones o la resciliación del contrato y, en ambos casos, la indemnización de los perjuicios (Consejo de Estado, 2019, Sent. 43.631).

Abordados estos últimos elementos conceptuales del principio de planeación, resulta esencial precisar diferentes aspectos prácticos. Sin duda, considerar que la planeación conlleva a la nulidad absoluta del contrato, genera múltiples dificultades para las entidades públicas. Es común que, por las dinámicas propias de la Administración Pública, las entidades incurran en errores al momento de estructurar los contratos, los cuales podrían tener la magnitud de entorpecer la ejecución de los mismos. Si bien es claro que esta desatención del deber de planeación no puede quedar impune, también es cierto que la declaratoria de nulidad del contrato podría imposibilitar el cumplimiento de los fines del Estado, que son, esencialmente, prestar los servicios públicos y garantizar el interés general. 
Una de las situaciones más complejas se relaciona con las restituciones mutuas. Bajo el tenor del Artículo 48 de la Ley 80 de 1993, si un contrato se encuentra viciado de nulidad absoluta por objeto ilícito

[...] el ejecutor o prestador del objeto contractual tiene derecho a ser restituido por el valor equivalente a las prestaciones ejecutadas, en cuanto la entidad se hubiere beneficiado con éstas, en virtud de que le hubiesen servido para la satisfacción de un interés o intereses públicos (Consejo de Estado, 2019, Sent. 61.720).

De este modo, si un contrato se declara nulo por violación del deber de planeación, deberá determinarse si el mismo se ejecutó -total o parcialmente-, y si dicha ejecución satisfizo el interés público, puesto que, en este caso, no habrá lugar a restituciones mutuas.

Por el contrario, si el contrato no se ejecutó, o si lo ejecutado no beneficia a la entidad, deberá ordenarse la restitución de lo pagado. Para comprender mejor las implicaciones de lo anteriormente expuesto, piénsese en las siguientes variables: En primer lugar, si la entidad entregó un anticipo o un pago anticipado, y el contratista no ejecutó la obra, o lo ejecutado no beneficia a la entidad, dichos valores deberán restituirse debidamente actualizados. En segundo lugar, si la obra se ejecutó, y dicha ejecución satisfizo el interés general, la entidad deberá pagarle dichas prestaciones al contratista (si se había entregado un anticipo o un pago anticipado, estos valores se amortizarán). En tercer lugar, si la ejecución fue parcial, pero la entidad no se benefició, el contratista deberá restituir lo pagado; en este caso, la Administración deberá iniciar los esfuerzos tendientes a adelantar un nuevo procedimiento de selección, con el fin de culminar la obra.

Como estos, existen numerosos supuestos que dilucidan las implicaciones que se generan cuando un contrato es declarado nulo ${ }^{11}$. Por supuesto, no se

11 En este punto, es necesario aclarar lo siguiente: de la lectura de los párrafos precedentes, podría colegirse que la violación del deber de planeación habilita a la entidad estatal a declarar la nulidad del contrato, en los términos del artículo 45 de la Ley 80 de 1993, que dispone: "La nulidad absoluta podrá ser alegada por las partes, por el agente del ministerio público, por cualquier persona o declarada de oficio, y no es susceptible de saneamiento por ratificación. En los casos previstos en los numerales 10., 2o. y 4o. del artículo anterior, el jefe o representante legal de la entidad respectiva deberá dar por terminado el contrato mediante acto administrativo debidamente motivado y ordenará su liquidación en el estado en que se encuentre". Sin embargo, el desconocimiento de este principio no permite la declaratoria de nulidad en sede administrativa, en tanto la causal de nulidad absoluta configurada es el objeto ilícito, mas no alguna de las contempladas en el artículo 44 de la Ley 80 , especialmente, la relativa a celebrar el contrato en contra de expresa prohibición 
reprueba la institución de la nulidad, en tanto esta, cuando es procedente, garantiza la conservación de la legalidad, y es necesaria para desestimular la celebración de contratos en contra de expresa prohibición legal, con desviación de poder, o con personas incursas en causales de inhabilidad; sin embargo, su procedencia, como se ha reiterado en varias oportunidades, debe obedecer a una habilitación legislativa, y no a una interpretación extensiva del juez.

Así, es claro que, desde un punto de vista conceptual y práctico, la tesis de la Subsección C de la Sección Tercera del Consejo de Estado, pese a servir a una finalidad loable, como lo es proteger el orden jurídico, adolece de deficiencias conceptuales, en tanto desconoce el principio de taxatividad, al tiempo que representa un sinnúmero de problemas prácticos para el buen funcionamiento de la Administración Pública.

\section{Conclusiones}

En el transcurso de estas líneas se ha analizado el principio de planeación en la contratación estatal, determinando que es una institución de creación jurisprudencial, cuya existencia, pese a no reposar en una disposición positiva, se deriva de la normativa que regula los planes de desarrollo, los procedimientos de selección, y los demás principios de la contratación. Del recuento doctrinal y jurisprudencial realizado en el título primero, se colige que: (i) este principio busca que la apertura del proceso, la suscripción del contrato, su posterior ejecución, y su liquidación, no sean el producto de una tarea improvisada, sino que obedezcan a actuaciones programadas y preconcebidas; (ii) es un principio bifronte, por lo que debe ser observado tanto por la entidad estatal como por el contratista; (iii) su alcance e intensidad varían dependiendo del

\footnotetext{
constitucional o legal. Ciertamente, el Consejo de Estado ha afirmado que, como este principio no se encuentra tipificado en la ley, no puede derivar en las causales de nulidad del artículo 44, pero sí en otras, como las del derecho común. En palabras del alto tribunal: "Para que se configure la causal de nulidad prevista en el numeral $2^{\circ}$ del artículo 44 de la Ley 80 de 1993, esto es que el contrato se celebre contra expresa prohibición legal o constitucional es menester que haya una violación al régimen de prohibiciones y que esa prohibición sea explícita, razón por la cual no toda transgresión a una prohibición conduce a estructurar esta precisa causal aunque por supuesto habrá de configurar otra. En este orden de ideas, si se desacata una prohibición genérica o una prohibición implícita del estatuto contractual [como la derivada del principio de planeación], el contrato será absolutamente nulo por violar el régimen legal pero la causal no será la enlistada en el numeral $2^{\circ}$ del artículo 44 de la Ley 80 de 1993 sino una diferente según el caso" (Consejo de Estado, 2013, Sents. 27.315, 24.809 y 26.637). De este modo, es claro que, en virtud de la tesis de la Subsección $C$, el juez es el único competente para declarar la nulidad de los contratos por desatención del principio de planeación.
} 
tipo contractual, y (iv) de la noción de este principio no se deriva una conexión directa con las causales de nulidad absoluta de los contratos estatales.

Da igual modo, se abordó la tesis desarrollada por la Subsección C de la Sección Tercera en las sentencias 27.315, 24.809 y 26.637, en virtud de la cual la falta de planeación deriva en la nulidad absoluta del contrato por ilicitud en el objeto, ya que, según el derecho privado, esto es lo que ocurre cuando se desconoce un mandato imperativo, como es el de planificar los contratos. Por supuesto, esta tesis no fue pacífica en la jurisprudencia, por lo que se expusieron los argumentos contenidos en el salvamento de voto de los fallos, y en las sentencias de tutela que dejaron sin efectos la providencia 24.809.

Posteriormente, y luego de precisar las nociones de nulidad absoluta y de objeto ilícito, se contrastó la teoría de la subsección C con el principio de taxatividad de las sanciones, concluyendo que aquella aplica una sanción a partir de una interpretación extensiva, lo cual representa un desconocimiento del carácter taxativo de las sanciones, que se traduce en una violación de los principios de legalidad y debido proceso.

Esta es la conclusión más importante del trabajo, por cuanto evidenció cómo el juez contencioso administrativo definió los alcances de una causal de nulidad, pese a que dicha competencia, en virtud de la jurisprudencia de la Corte Constitucional, es exclusiva del legislador.

Luego, se explicó el sentido que ha tenido el principio de planeación en la jurisprudencia reciente, relacionándolo con la figura del incumplimiento. En este punto, se coligió que las fallas en la planeación podrían traducirse en incumplimiento de las obligaciones, lo cual sería asumido por la entidad, en la medida de que el contratista hubiese cumplido con sus deberes como colaborador de la Administración. De este modo, si la falla en la planeación obedece a situaciones de responsabilidad exclusiva de la entidad, y esto genera retrasos en la ejecución del contrato, aquella deberá indemnizar los perjuicios causados al contratista. Por el contrario, si el contratista podía observar o cuestionar las condiciones del contrato, pero no lo hace, no podrá reclamar posteriormente un incumplimiento, por cuanto eso riñe con la buena fe.

En igual sentido, se presentaron algunas implicaciones prácticas que se derivan de la tesis de la Subsección C, como lo relacionado con las restituciones mutuas, o el trabajo que implica para la entidad iniciar nuevamente los procedimientos de selección para finalizar los contratos que quedaron 
inconclusos. En atención a este punto, es pertinente reiterar que, por supuesto, la desatención del deber de planeación no puede quedarse sin consecuencias. No obstante, es más eficiente recurrir a otro tipo de alternativas, como la modificación del contrato, el uso de los poderes excepcionales, o las multas, con el fin de evitar la paralización de los procesos adelantados por el Estado.

En todo caso, es igualmente claro que la Administración Pública debe comenzar a implementar estrategias reales, que permitan el cumplimiento del mandato imperativo de planificar los contratos, pues el Estado está en la obligación de respetar el orden jurídico, sin que su accionar deba condicionarse a la amenaza de una posible sanción.

\section{Referencias}

Alexy, R. (2011). Los derechos fundamentales y el principio de proporcionalidad. Revista Española de Derecho Constitucional, 91, 11-29.

Benavides, J.L. (2002). El contrato estatal. Entre el Derecho público y el Derecho privado. Universidad Externado de Colombia.

Consejo de Estado, Sección Tercera. (31 de agosto de 2006). Sentencia 14.287 [C.P.: Mauricio Fajardo Gómez].

Consejo de Estado, Sección Tercera. (29 de agosto de 2007). Sentencia 14.854 [C.P.: Mauricio Fajardo Gómez].

Consejo de Estado, Sección Tercera. (29 de agosto de 2007). Sentencia 15.324 [C.P.: Mauricio Fajardo Gómez].

Consejo de Estado, Sección Tercera. (05 de junio de 2008). Sentencia 8.031 [C.P.: Mauricio Fajardo Gómez].

Consejo de Estado, Sección Tercera, Subsección C. (31 de enero de 2011). Sentencia 17.767 [C.P.: Olga Mélida Valle de De la Hoz].

Consejo de Estado, Sección Tercera, Subsección C. (28 de marzo de 2012). Sentencia 22.471 [C.P.: Jaime Orlando Santofimio Gamboa].

Consejo de Estado, Sección Tercera, Subsección B. (28 de mayo de 2012). Sentencia 21.489 [C.P.: Ruth Stella Correa Palacio].

Consejo de Estado, Sección Tercera, Subsección C. (24 de abril de 2013). Sentencia 27.315 [C.P.: Jaime Orlando Santofimio Gamboa].

Consejo de Estado, Sección Tercera, Subsección C. (13 de junio de 2013). Sentencia 24.809 [C.P.: Jaime Orlando Santofimio Gamboa].

Consejo de Estado, Sección Tercera, Subsección C. (13 de junio de 2013). Sentencia 26.637 [C.P.: Jaime Orlando Santofimio Gamboa].

Consejo de Estado, Sección Cuarta. (21 de agosto de 2014). Sentencia 11001-03-15000-2013-01919-00 [C.P.: Hugo Fernando Bastidas Bárcenas].

Consejo de Estado, Sección Tercera, Subsección C. (20 de octubre de 2014). Sentencia 24.809 [C.P.: Jaime Orlando Santofimio Gamboa]. 
Consejo de Estado, Sección Quinta. (27 de noviembre de 2014). Sentencia 11001-0315-000-2013-01919-01 [C.P.: Lucy Jannette Bermúdez].

Consejo de Estado, Sección Tercera, Subsección C. (10 de diciembre de 2015). Sentencia 51.489 [C.P.: Jaime Orlando Santofimio Gamboa].

Consejo de Estado, Sección Tercera, Subsección B. (11 de diciembre de 2015). Sentencia 24.636 [C.P.: Ramiro Pazos Guerrero].

Consejo de Estado, Sección Tercera, Subsección C. (23 de octubre de 2017). Sentencia 55.855 [C.P.: Jaime Orlando Santofimio Gamboa].

Consejo de Estado, Sección Tercera, Subsección C. (15 de diciembre de 2017). Sentencia 50.045 [C.P.: Jaime Orlando Santofimio Gamboa].

Consejo de Estado, Sección Segunda, Subsección A. (25 de enero de 2018). Sentencia 1501-12 [C.P.: Gabriel Valbuena Hernández].

Consejo de Estado, Sección Tercera, Subsección A. (06 de febrero de 2019). Sentencia 61.720 [C.P.: Marta Nubia Velásquez Rico].

Consejo de Estado, Sección Tercera, Subsección A. (08 de mayo de 2019). Sentencia 59.309 [C.P.: Marta Nubia Velásquez Rico].

Consejo de Estado, Sección Tercera, Subsección A. (30 de mayo de 2019). Sentencia 43.631 [C.P.: Carlos Alberto Zambrano].

Consejo de Estado, Sección Tercera, Subsección B. (03 de abril de 2020). Sentencia 48.676 [C.P.: Alberto Montaña Plata].

Consejo de Estado, Sección Tercera, Subsección A. (03 de abril de 2020). Sentencia 61.500 [C.P.: Marta Nubia Velásquez Rico].

Consejo de Estado, Sección Tercera, Subsección B. (05 de mayo de 2020). Sentencia 45.816 [C.P.: Martín Bermúdez Muñoz].

Consejo de Estado, Sección Tercera, Subsección A. (19 de junio de 2020). Sentencia 44.420 [C.P.: María Adriana Marín].

Consejo de Estado, Sección Tercera, Subsección A. (19 de marzo de 2021). Sentencia 42.135 [C.P.: María Adriana Marín].

Corte Constitucional. (05 de julio de 2001). Sentencia C-709 [M.P.: Alfredo Beltrán Sierra].

Corte Constitucional. (18 de mayo de 2004). Sentencia C-475 [M.P.: Marco Gerardo Monroy Cabra].

Corte Constitucional. (25 de abril de 2012). Sentencia C-300 [M.P.: Jorge Ignacio Pretelt Chaljub].

Corte Constitucional. (13 de mayo de 2015). Sentencia C-284 [M.P.: Mauricio González Cuervo].

Corte Suprema de Justicia, Sala de Casación Penal. (21 de octubre de 2013). Sentencia 41.665 [M.P.: María del Rosario González y Gustavo Enrique Malo].

Corte Suprema de Justicia, Sala de Casación Penal. (23 de noviembre de 2016). Sentencia 46.037 [M.P.: Patricia Salazar Cuellar].

Dávila Vinueza, L.G. (2003). Régimen Jurídico de la Contratación Estatal. Segunda edición. Editorial Legis.

Dávila Vinueza, L.G. (2016). Régimen Jurídico de la Contratación Estatal. Tercera edición. Editorial Legis.

Escobar Gil, R. (2003). Teoría general de los contratos de la Administración Pública. Segunda edición. Editorial Legis. 
Matallana Camacho, E. (2013). Manual de contratación de la Administración Pública en Colombia. Tercera Edición. Universidad Externado de Colombia.

Ospina Fernández, G. y Ospina Acosta, E. (2014). Teoría General del Contrato y del Negocio Jurídico. Séptima edición. Editorial Temis.

Rodríguez Rodríguez, L. (2011). El equilibrio económico en los contratos administrativos. Derecho PUCP, 66, 55-87. ISSN. 0251-3420.

Santofimio Gamboa, J.O. (2009). Aspectos relevantes de la reciente reforma a la Ley 80 de 1993 y su impacto en los principios rectores de la contratación estatal. Contratación Estatal. Estudios sobre la reforma contractual. Universidad Externado de Colombia.

Yong, S. (2013). El contrato Estatal en el contexto de la Nueva Legislación. Editorial Jurídica Ibáñez. 